\title{
A fuzzy decision making method for outsourcing activities
}

\author{
Zahra Afrandkhalilabad* and Emad Roghanian
}

Department of Engineering, K.N.Toosi University of Technology, Tehran, Iran

\begin{tabular}{|c|c|}
\hline A R T I C L E I N F O & A B S T R A C T \\
\hline $\begin{array}{l}\text { Article history: } \\
\text { Received August 25, } 2012 \\
\text { Received in revised format } \\
25 \text { September } 2012 \\
\text { Accepted } 4 \text { October } 2012 \\
\text { Available online } \\
\text { October } 52012 \\
\text { Keywords: } \\
\text { Outsourcing }\end{array}$ & $\begin{array}{l}\text { Optimization of outsourcing operations plays an important role on development and progress } \\
\text { for modern organizations. One important question in optimization process is to find a tradeoff } \\
\text { between advantage and disadvantage of outsourcing and make appropriate decision whenever } \\
\text { outsourcing action is necessary. In fact, there are several cases where outsourcing is not } \\
\text { implemented properly and organizations suffer from the consequences. The primary purpose of } \\
\text { this paper is to investigate various aspects of outsourcing to facilitate decision-making process } \\
\text { in fuzzy environments. The preliminary results detect some of the necessary actions for } \\
\text { decision making operations. }\end{array}$ \\
\hline
\end{tabular}

Fuzzy

Hierarchy analysis process

Decision making

\section{Introduction}

One of the primary concerns in production planning is to determine appropriate activities for outsourcing operations. The primary question is on how to separate good activities for outsourcing and how to choose appropriate supplier for such operations. This question has been viewed by some as a classic make-or-buy decision making or decision has been assumed to have a vertical merge. As outsourcing is considered, firms fall into decision making process in which if they need to reverse the previously "made" decision i.e. a reshaping of existing firm boundaries happens in outsourcing. The concept of outsourcing involves taking some steps, which starts with the development of a sound business case for this purpose, continues with implementation of the external sourcing model and ends up with the management of the relationship with the provider. Outsourcing has come around as a widespread and transformational business practice. As Deloitte Consulting study has shown (Landis et al., 2005), 64\% of the participants in their survey indicated that they had taken outsource back inhouse and $44 \%$ could not make a distinction for the cost savings. In the meantime, they could figure out that $20-25 \%$ of all outsourcing relationships fail within 2 years and half fail in 5 years (Doig et al.,

* Corresponding author.

E-mail addresses: z.afrand@yahoo.com (Z. Afrandkhalilabad) 
2001). The most recent study on 300 business executives conducted by Deloitte revealed the need for improved outsourcing practices. The study illustrated that only $34 \%$ were satisfied with the provider's innovation and $61 \%$ claimed that they needed to "escalate" problems to senior management within the first year (Robinson et al., 2008). In addition, it has been mentioned that $75 \%$ of interviewed service providers felt that their clients were ill prepared for the purpose of outsourcing.

In sequence to make sure about the long-term success, management of an outsourcing relationship seems vital; however, organizations often fall behind providing the necessary skills and expertise for this purpose (Robinson et al., 2008; Harland et al., 2005; Power et al., 2004; Spekman \& Caraway, 2006). For instance, Lego-a Danish company implemented outsourcing of its manufacturing activities in 2006 to Flextronics and took it back in-house in 2008. The machines specificity prevented outstanding economies of scale from being achieved (Barthélemy, 2011). It showed that coordination and control of the production were of more complication in-house and it had been worsened by divergences and misalignments between these two mentioned companies) (Larsen, 2010).

When there is a satisfactory outsourcing, it can lead to the fact that client organization will receive benefits, which they might not have been able to obtain by performing the activity in-house. However, there is no guarantee for such profits and probable risks should be taken into value as well if the before made arrangement is not successful. As a result, the contributing criteria to ensure there will be a positive outcome for long-term not just the short-term process should be distinguished beforehand.

\subsection{The definition of outsourcing}

In traditional sense, outsourcing stands for "outside resource using" (U, 1996) 1. Outside means to create a value form without, not within, the company. This focus is not an end on its own, it involves a strategic perspective on external resources but realizing these resources cannot be sufficient. These resources must be used by a company to improve its position in a competition (U., 2000). Outsourcing nowadays has turned to be an important business concept and approach and when the products and services are provided more effectively and efficiently by an outside supplier, then a competitive advantage may be obtained. It is an agreed upon contract that a company hands over a part of their existing internal activity to another one (McCarthy I, 2004). Arnold (U., 2000) presents an outsourcing model, which involves four major elements: outsourcing subject, outsourcing object, outsourcing partner and outsourcing design.

\subsection{Review of literature}

Outsourcing has become a prevalent management strategy following the organizational competiveness. Therefore, this has been and will be a favorable subject for academic research as the reviews prove this claim (Hätönen, \& Eriksson, 2009; Kremic, et al., 2006) most of them have put the main emphasis on the functions which require an outsourcing ((Hafeez et al., 2007; Wu \& Park, 2009). Outsourcing includes how to select a service provider (Chen \& Chen, 2006; Lasch \& Janker, 2005; Rese, 2006; Tseng, \& Lin, 2005), where to outsource (Bunyaratavej et al., 2007; Bunyaratavej et al., 2008; Graf \& Mudambi, 2005; Hätönen, 2009; Zaheer et al., 2009; Bunyaratavej et al. , 2008) and the corresponding benefits and risks with outsourcing (Di Gregorio et al., 2009; Harland et al., 2005; Hoecht, 2006; Kremic et al., 2006; Jennings, 2002). All of these matters are pertinent to the initial stages of this process. In sequence to meet the mutual goal, outsourcing has been completed in a more strategic way, cooperation, collaboration and co-development. As a result, a close and longterm relationship is required to make sustainable competitive advantage (Franceschini et al., 2003; Handley \& Benton, 2009; Helper, \& Sako, 1995; Lee, \& Kim, 1999; McHugh et al., 2003; Handley \& Benton, 2009; Nistorescu \& Barbu, 2009). Lacity (1996) claimed that a decision matrix for IS outsourcing would consist of business, economic and technical criteria. Ketler and Walstorm (1993)

thought of categorization of outsourcing decisions to be personal, economic, risk versus control 
characteristics of outsourced data/segment, organizational characteristics, vendor and contract matters. Udo (1996) used the AHP to suggest a suitable IS outsourcing decision model and grouped determinants into strategic importance, vendor matters, customer interests, and employee interests.

\subsection{Fuzzy Logic}

Fuzzy theory has been introduced to handle uncertainty associated with different events in real-world case studies (Zadeh, 1965). The proposed study of this paper uses fuzzy logic to handle uncertainty associated with outsourcing activates. There are different types of fuzzy numbers and the proposed study of this paper uses triangular form. A triangular fuzzy number is a specific set $\tilde{\mathrm{A}}$ and its membership function $\mu_{\tilde{\mathrm{A}}}(x)$ is a continuous linear function.

Definition 1. Let $X$ be universe of discourse, $\tilde{\mathrm{A}}$ is a fuzzy subset of $X$ such that for all $x \in X$. $\mu_{A}(x) \epsilon[0,1]$, which is assigned to stand for the membership of $x$ to $\tilde{\mathrm{A}}$, and $\mu_{\tilde{\mathrm{A}}}(x)$ is called the membership function of fuzzy set $\tilde{A}$.

Definition 2. A fuzzy number $\tilde{A}$ is a convex and normalized fuzzy set of $X \subseteq R$.

Definition 3. A triangular fuzzy number is defined by its basic particulars, which is:

$\mu_{\tilde{A}}(x)=\left\{\begin{array}{cc}0 & x \leq 1 \\ \frac{x-l}{m-l} & l \leq x \leq m \\ \frac{u-x}{u-m} & m \leq x \leq u \\ 0 & u \leq x\end{array}\right.$

where $l$ and $u$ correspond to the lower and upper bounds of the fuzzy number $\tilde{\mathrm{A}}$, respectively, and $m$ is the midpoint. The triangular fuzzy number is indicated as $\tilde{\mathrm{A}}=(\mathrm{l}, \mathrm{m}, \mathrm{u})$. Arithmetic operations between fuzzy numbers or a fuzzy number and crisp number are defined in Zadeh (1965) by standard fuzzy arithmetic operations.

\subsection{Analytic hierarchy process (AHP)}

Perhaps the most inventive duty in making a decision is to choose the criteria that are important for that decision. The AHP subdivides a complex decision-making problem or planning matter into its parts or levels, and arranges these levels into an ascending hierarchic order. At each level of the hierarchy, the parts are compared relative to each other using a pairwise comparison plan. The parts of a given level are related to an adjacent upper level and thereby generate merge across the levels of the hierarchy. The result of this systematic process is a set of priorities or relative importance, or method of scaling between the various actions or alternatives. The AHP allows its users flexibility in constructing a hierarchy to fit their needs. The AHP also provides an effective structure for group decision making by imposing a discipline on the group's thought processes. The necessity of assigning a numerical value to each variable of the problem helps decision makers maintain cohesive thought patterns by deriving the relative weight of each part of the hierarchy: criteria and alternatives. In this manner, one determines the optimum alternative. The AHP has been applied successfully to a variety of problems in planning, prioritization, resource allocation, conflict resolution, decision making, and forecasting. It is not possible to evaluate outsourcing activities accurately by using traditional financial techniques only, since most of the costs and benefits of such activities are real, which can be defined by using linguistic variables. For this reason, this paper proposes a fuzzy multi criteria decision making methodology based on AHP for scoring of each sub-criteria and criteria for outsourcing activities. 


\section{The proposed model}

The proposed model of this paper has two parts. The first part of the proposed model has the following steps.

Step 1: The DMs are required to review all information associated with the outsourcing activities and company. All DMs having different comments could have different impacts on the final decision, a fuzzy environment based weighting is implemented in the model to calculate the DMs' competence. For this aim, each DM is asked to evaluate the competency of other DM. Each DM evaluating the other DMs, he/she is asked to perform this task on the basis of his/her experiences, knowledge, about activities and outsourcing activities. For $m$ DMs in the evaluation group, the $i^{\text {th }} \mathrm{DM}$ is assigned a weight, where $C_{i} \in[0,1]$, and $C_{1}+C_{2}+\cdots+C_{m}=1$.The sub-criteria maintains impacts on the each criteria in a hierarchical structure. Therefore, each DM can give fuzzy scales for sub-criterion and compares every sub-criterion pair-wise in its corresponding group structured in the hierarchy scales if he/she is not sure about the exact numerical values. To overcome these shortcomings, a modified fuzzy AHP is used in this study. In the first stage, the DMs are required to compare every attribute pair-wise in their corresponding group structured in the hierarchy, and define scores of the outsourcing firms against these sub-criteria. They are encouraged to give fuzzy scales if they are not sure about the exact numerical values.

\section{Step 2}

After having the individual TFN scores for the sub-criteria, an aggregation into a group evaluation is performed by applying the fuzzy weighted trapezoidal averaging operator as in Eq. (1).

$\widetilde{S}_{i}=\tilde{S}_{i 1} \otimes C_{1} \oplus \tilde{S}_{i 2} \otimes C_{2} \oplus \ldots . . \oplus \tilde{S}_{i m} \otimes C_{m}$

where $\widetilde{\mathrm{S}}_{\mathrm{i}}$ is the fuzzy aggregated score of the sub-criterion, $\widetilde{\mathrm{S}}_{1}, \widetilde{\mathrm{S}}_{2}, \ldots, \widetilde{\mathrm{S}}_{\mathrm{m}}$ are the TFN scores of this sub-criteria measured by $\mathrm{m} D M s ; \mathrm{DM}_{1}, \mathrm{DM}_{2}, \ldots, \mathrm{DM}_{\mathrm{m}}$, respectively; $\otimes$ and $\oplus$ denote the fuzzy multiplication and addition operators, respectively.

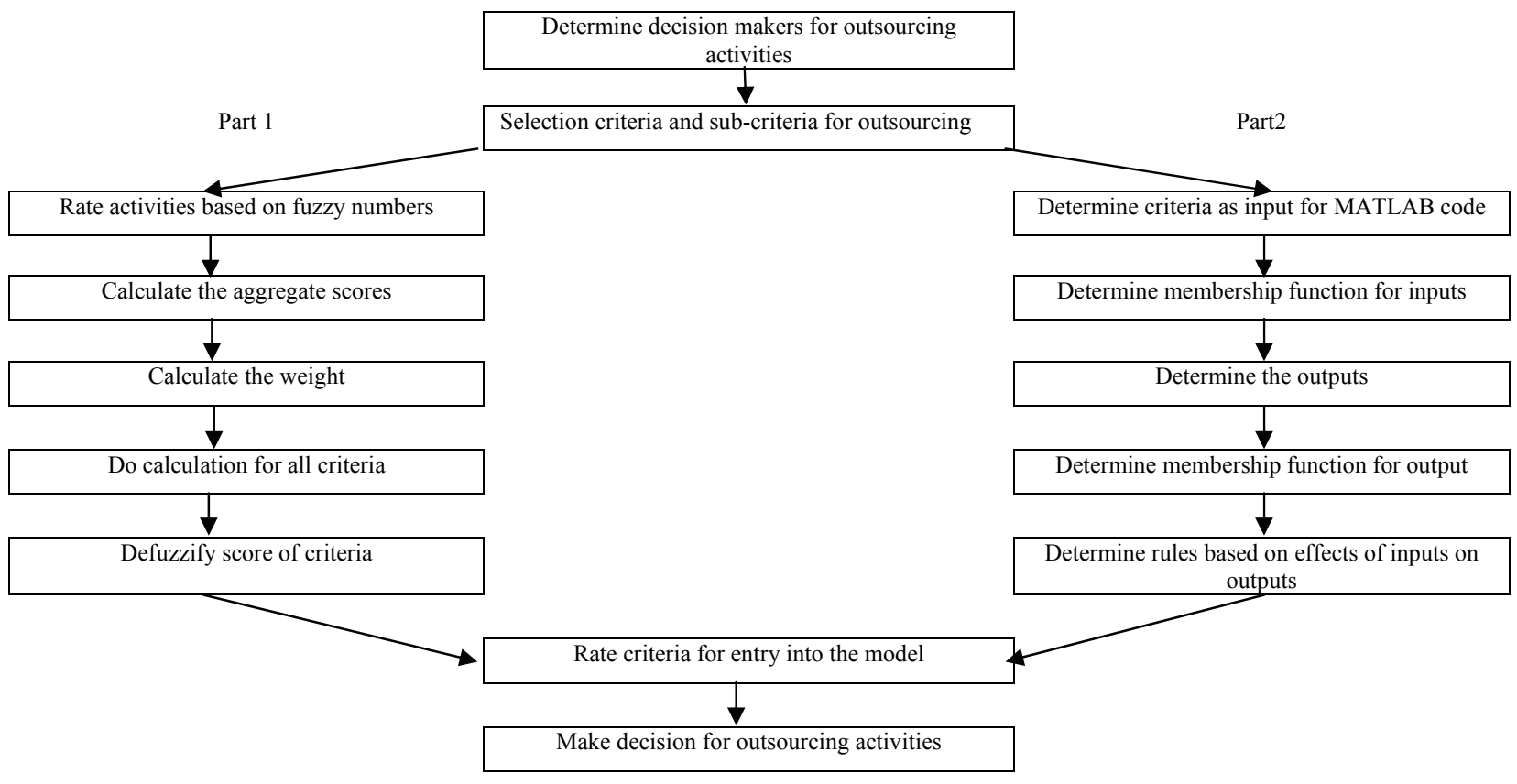

Fig. 1. The proposed model

$C_{1}, C_{2}, \ldots, C_{m}$ are the weights allocated to $\mathrm{DM}_{1}, \mathrm{DM}_{2}, \ldots, \mathrm{DM}_{\mathrm{m}}$, respectively. Similarly, the aggregation of the comparisons of the sub-criteria is defined as in Eq. (2) 
$\tilde{a}_{i j}=\tilde{a}_{i j 1} \otimes C_{1} \oplus \tilde{a}_{i j 2} \otimes C_{2} \oplus \ldots . \oplus \tilde{a}_{i j m} \otimes C_{m}$

where $\tilde{\mathrm{a}}_{\mathrm{ij}}$ is the aggregated fuzzy scale of sub-criteria compared with sub-criteria $j$ for $i, j=1,2, \ldots$, $n ; \tilde{a}_{\mathrm{ij} 1}, \tilde{a}_{\mathrm{ij} 2}, \ldots \tilde{a}_{\mathrm{ijm}}$ are the corresponding TFN scales sub-criteria compared with sub-criteria $j$ measured by $\mathrm{DMs} ; \mathrm{DM}_{1}, \mathrm{DM}_{2}, \ldots, \mathrm{DM}_{\mathrm{m}}$, respectively. After having all the required aggregated TFNs, it is now time for defuzzification to find the representative crisp numbers. Comsider an aggregated TFN, $\widetilde{a}_{i j}=(l, m, u)$ the representative crisp value $\tilde{a}_{i j}$ can be obtained by Eq. (3).

$a_{i j}=\frac{(l+m+u)}{3}$

Let $A_{1}, A_{2}, \ldots, A_{n}$ be a set of sub-criteria in one group, pair-wise comparisons between $A_{i}$ and $A_{j}$ in the same group yield an n-by-n matrix defined as in Eq. (4). Where $a_{i i}=1, a_{j i}=1 / a_{i j}$

$\mathrm{A}=a_{i j}=\left[\begin{array}{ccc}1 & \cdots & a_{i j} \\ \vdots & \ddots & \vdots \\ \frac{1}{a_{i j}} & \cdots & 1\end{array}\right] \mathrm{i}, \mathrm{j}=1,2,3, \ldots, \mathrm{n}$

The priority weights of attributes in matrix A can then be calculated by using the arithmetic averaging method where $w_{i}$ is the group weight of $A_{i}$ with Eq.(5)

$w_{i}=\frac{1}{n} \sum_{i=1}^{n} \frac{a_{i j}}{\sum_{k=1}^{n} a_{k j}}$

Finally, according to Eq. (6), the resulting fuzzy numbers can be converted to a normal non-fuzzy points each criteria for input of the model.

$\widetilde{F S}=\sum_{i=1}^{n} w_{i} * \tilde{S}_{i}$

In part two is given as follow:

Inductive Sogno's phase model has been practiced in this paper. As mentioned earlier, three criteria are decisive for the phase inductive model: 1-input, 2-regulations and 3-output. Each of these features can be determined by as the following:

1.input:In this model, input involve $\mathrm{k}^{\text {th }}$ criteria for $\mathrm{k}=1,2, \ldots, \mathrm{p}$

2.Regulations:Regulations play the most important role in the presented model and these regulations are the mean of criteria related to the outsourcing and they might have a different tendency to outsourcing. If the criteria is in the direction of outsourcing, the outsourcing tendency increases and if this is in the opposite direction, this tendency decreases and if the features of outsourcing are equal to the opposite features of outsourcing, they can neutralize their effects. In general, there can be models and it can be said that the number of solving regulations of this model will ber ${ }^{k}$ phase rules for $\mathrm{k}=1$, $2, \ldots, p$ and $r$ show mood of each criteria.

3.Output:The output of this model has different phase cases related to DMs.

Now the phase model is available to be used, DMs can put score of each criteria (in part 1) as input, at least DM decisions based on model output. 


\section{Case study}

The management decided to outsource their activities and decisions based on the third generation. The management decided to outsource their activities and decisions based on the third generation. In the first step, each DM is asked to evaluate the competency of other two. After a short meeting, the group comes up with the idea of having equal weights. Therefore the expert weight is determined as 0.33. After that, they evaluated the considered criteria and sub-criteria as in Table1. Each DM provides a decision about his/her judgment as a precise numerical value, a possible range of numerical values, a linguistic term, or a fuzzy number. Then these evaluations are converted into TFNs as defined in Table 4 shows scores and converted TFN of outsourcer selection criteria for FirmA. The aggregations of the DMs evaluations are calculated by using Eq. (1) and show in table 1. In the next stage, the DMs evaluate the selection criteria by using pair-wise comparison. DMs can evaluation weight for each sub-criteria by using Eq. (2), Eq. (3), Eq. (4), Eq. (5) and show in Table 5.

\section{Table 1}

Criteria and sub-criteria of the proposed study

\begin{tabular}{|c|c|c|c|}
\hline \multirow{2}{*}{$\mathrm{U}_{1}$} & \multirow{2}{*}{ Quality } & Capability of process quality & $\mathrm{U}_{11}$ \\
\hline & & matching up with the international standards & $\mathrm{U}_{12}$ \\
\hline \multirow{5}{*}{$\mathrm{U}_{2}$} & \multirow{5}{*}{ Organization } & Core competence & $\mathrm{U}_{21}$ \\
\hline & & Flexibility & $\mathrm{U}_{22}$ \\
\hline & & Employee Morale & $\mathrm{U}_{23}$ \\
\hline & & Information Security & $\mathrm{U}_{24}$ \\
\hline & & Loss Of Management Control & $\mathrm{U}_{25}$ \\
\hline \multirow{3}{*}{$\mathrm{U}_{3}$} & \multirow{3}{*}{ Technology } & The capacity of technology & $\mathrm{U}_{31}$ \\
\hline & & Combining Technology \& In Innovation Capacity & $\mathrm{U}_{32}$ \\
\hline & & Technological uncertainty & $\mathrm{U}_{33}$ \\
\hline \multirow{2}{*}{$\mathrm{U}_{4}$} & \multirow{2}{*}{ Cost } & Apparent cost & $\mathrm{U}_{41}$ \\
\hline & & Hidden Cost & $\mathrm{U}_{42}$ \\
\hline \multirow{3}{*}{$\mathrm{U}_{5}$} & \multirow{3}{*}{ Environment } & Vendor's Service quality & $\mathrm{U}_{51}$ \\
\hline & & Number of Supplier & $\mathrm{U}_{52}$ \\
\hline & & Competitive Position & $\mathrm{U}_{53}$ \\
\hline
\end{tabular}

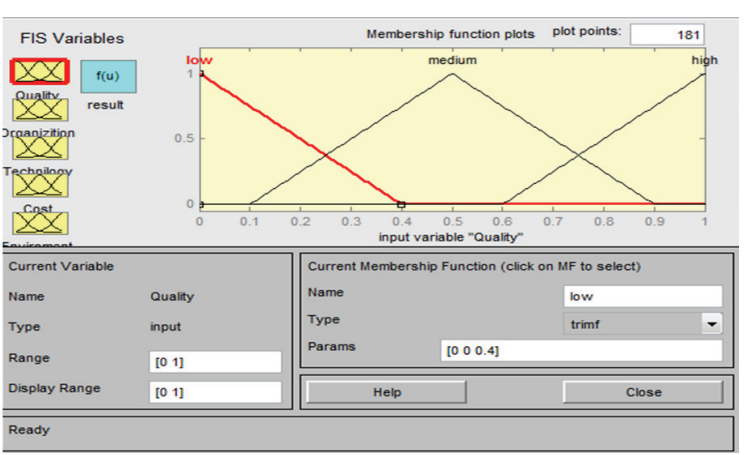

Fig. 2. Membership of inputs

\begin{tabular}{|c|c|}
\hline & \\
\hline & 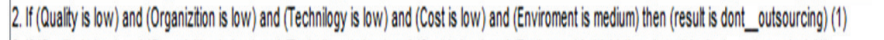 \\
\hline & \\
\hline & \\
\hline & \\
\hline & uring) (1) \\
\hline & ad (Organiztion is bow) and (Technilogy is bw) and (COS \\
\hline & nd (Organizition i l bow) and (Technilogy is bow) and (Cos \\
\hline & 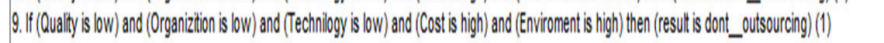 \\
\hline & \\
\hline & \\
\hline & \\
\hline
\end{tabular}

Fig. 3. Different fuzzy rules

In part 2, DMs have to determine input and their memberships and show in Fig 2, regulation and output of model. In the example, model has 5 criteria and 15 sub-criteria. These regulations are the mean of indicators (5 inputs having three moods) related to the outsourcing and they might have a high, low or indifferent tendency to outsourcing. Model has 243 regulations (See Fig. 3) with one output with three choices as follows,

- Weak tendency to outsourcing(don't outsourcing)

- Neutral tendency to outsourcing(don't care)

- Strong tendency to outsourcing(do outsource) 
Each DM provides a decision about his/her judgment as a precise numerical value, a possible range of numerical values, a linguistic term, or a fuzzy number. Then these evaluations are converted into TFNs as defined in Table 2 shows scores and converted TFN of outsourcer selection criteria.

Table 2

Fuzzy numbers corresponding to priority in pair comparisons

\begin{tabular}{lccc}
\hline Linguistic variable & Low & Medium & High \\
\hline Fuzzy number & $(0,0,0.4)$ & $(0.1,0.5,0.9)$ & $(0.6,0.8,1)$ \\
\hline
\end{tabular}

The aggregations of the DMs evaluations are calculated using Eq. (1) and the results are given in Table 3.

Table 3

Score and converted TFN for Selection sub-criteria

\begin{tabular}{|c|c|c|c|c|c|c|c|c|}
\hline \multirow{2}{*}{ criteria } & \multirow[b]{2}{*}{ Sub-criteria } & \multicolumn{2}{|c|}{$\begin{array}{l}\text { Decision Make } 1 \\
c_{1}=0.33\end{array}$} & \multicolumn{2}{|c|}{$\begin{array}{l}\text { Decision Make } 2 \\
c_{2}=0.33\end{array}$} & \multicolumn{2}{|c|}{$\begin{array}{l}\text { Decision Make } 3 \\
c_{3}=0.33\end{array}$} & \multirow[t]{2}{*}{ Aggregation } \\
\hline & & score & converted TFN & score & converted TFN & score & converted TFN & \\
\hline \multirow{2}{*}{$U_{1}$} & $\mathrm{U}_{11}$ & $\mathrm{~L}$ & $(0,0,4 / 10)$ & $\mathrm{L}$ & $(0,0,4 / 10)$ & M & $(1 / 10,5 / 10,9 / 10)$ & $(0.033,0.156,0.561)$ \\
\hline & $\mathrm{U}_{12}$ & $\mathrm{~L}$ & $(0,0,4 / 10)$ & M & $(1 / 10,5 / 10,9 / 10)$ & $\mathrm{L}$ & $(0,0,4 / 10)$ & $(0.033,0.156,0.561)$ \\
\hline \multirow{5}{*}{$U_{2}$} & $\mathrm{U}_{21}$ & $\mathrm{M}$ & $(1 / 10,5 / 10,9 / 10)$ & $\mathrm{H}$ & $(6 / 10,8 / 10,10 / 10)$ & $\mathrm{H}$ & $(6 / 10,8 / 10,10 / 10)$ & $(0.429,0.693,0.957)$ \\
\hline & $\mathrm{U}_{22}$ & $\mathrm{H}$ & $(6 / 10,8 / 10,10 / 10)$ & M & $(1 / 10,5 / 10,9 / 10)$ & $\mathrm{L}$ & $(0,0,4 / 10)$ & $(0.231,0.429,0.759)$ \\
\hline & $\mathrm{U}_{23}$ & $\mathrm{~L}$ & $(0,0,4 / 10)$ & $\mathrm{H}$ & $(6 / 10,8 / 10,10 / 10)$ & $\mathrm{L}$ & $(0,0,4 / 10)$ & $(0.198,0.264,0.594)$ \\
\hline & $\mathrm{U}_{24}$ & $\mathrm{~L}$ & $(0,0,4 / 10)$ & $\mathrm{L}$ & $(0,0,4 / 10)$ & $\mathrm{H}$ & $(6 / 10,8 / 10,10 / 10)$ & $(0.198,0.264,0.594)$ \\
\hline & $\mathrm{U}_{25}$ & $\mathrm{H}$ & $(6 / 10,8 / 10,10 / 10)$ & $\mathrm{M}$ & $(1 / 10,5 / 10,9 / 10)$ & $\mathrm{L}$ & $(0,0,4 / 10)$ & $(0.231,0.429,0.759)$ \\
\hline \multirow{3}{*}{$U_{3}$} & $\mathrm{U}_{31}$ & $\mathrm{H}$ & $(6 / 10,8 / 10,10 / 10)$ & M & $(1 / 10,5 / 10,9 / 10)$ & M & $(1 / 10,5 / 10,9 / 10)$ & $(0.264,0.264,0.924)$ \\
\hline & $\mathrm{U}_{32}$ & $\mathrm{H}$ & $(6 / 10,8 / 10,10 / 10)$ & $\mathrm{H}$ & $(6 / 10,8 / 10,10 / 10)$ & $\mathrm{L}$ & $(0,0,4 / 10)$ & $(0.396,0.528,0.792)$ \\
\hline & $\mathrm{U}_{33}$ & M & $(1 / 10,5 / 10,9 / 10)$ & $\mathrm{L}$ & $(0,0,4 / 10)$ & $\mathrm{H}$ & $(6 / 10,8 / 10,10 / 10)$ & $(0.231,0.429,0.759)$ \\
\hline \multirow{2}{*}{$U_{4}$} & $\mathrm{U}_{41}$ & $\mathrm{M}$ & $(1 / 10,5 / 10,9 / 10)$ & $\mathrm{L}$ & $(0,0,4 / 10)$ & $\mathrm{L}$ & $(0,0,4 / 10)$ & $(0.033,0.165,0.561)$ \\
\hline & $\mathrm{U}_{42}$ & M & $(1 / 10,5 / 10,9 / 10)$ & $\mathrm{H}$ & $(6 / 10,8 / 10,10 / 10)$ & M & $(1 / 10,5 / 10,9 / 10)$ & $(0.264,0.264,0.924)$ \\
\hline \multirow{3}{*}{$U_{5}$} & $\mathrm{U}_{51}$ & $\mathrm{~L}$ & $(0,0,4 / 10)$ & $\mathrm{M}$ & $(1 / 10,5 / 10,9 / 10)$ & $\mathrm{H}$ & $(6 / 10,8 / 10,10 / 10)$ & $(0.231,0.429,0.759)$ \\
\hline & $\mathrm{U}_{52}$ & $\mathrm{H}$ & $(6 / 10,8 / 10,10 / 10)$ & $\mathrm{L}$ & $(0,0,4 / 10)$ & $\mathrm{L}$ & $(0,0,4 / 10)$ & $(0.198,0.264,0.594)$ \\
\hline & $\mathrm{U}_{53}$ & $\mathrm{H}$ & $(6 / 10,8 / 10,10 / 10)$ & $\mathrm{H}$ & $(6 / 10,8 / 10,10 / 10)$ & M & $(1 / 10,5 / 10,9 / 10)$ & $(0.264,0.264,0.924)$ \\
\hline
\end{tabular}

Now we can perform a pairwise comparison for each criterion, for instance, pairwise comparison for quality is demonstrated in Table 4.

\section{Table 4}

Pair-wise comparison and fuzzy aggregation of Quality

\begin{tabular}{|c|c|c|c|c|c|}
\hline Sub-criteria & Decision make & score & $\mathrm{U}_{11}$ & score & $\mathrm{U}_{12}$ \\
\hline \multirow{4}{*}{$\mathrm{U}_{11}$} & E1 & & \multirow{4}{*}{1} & $\mathrm{~L}$ & $(0,0,4 / 10)$ \\
\hline & E2 & & & M & $(1 / 10,5 / 10,9 / 10)$ \\
\hline & E3 & & & \multirow{2}{*}{\multicolumn{2}{|c|}{$\begin{array}{l}M \quad(1 / 10,5 / 10,9 / 10) \\
(0.05,0.33,0.733)\end{array}$}} \\
\hline & Aggregation & & & & \\
\hline \multirow{4}{*}{$\mathrm{U}_{12}$} & E1 & & $(0,0,10 / 4)$ & \multirow{4}{*}{\multicolumn{2}{|c|}{1}} \\
\hline & E2 & & \multirow{2}{*}{$\begin{array}{l}(10 / 1,10 / 5,10 / 9) \\
(10 / 110 / 510 / 9)\end{array}$} & & \\
\hline & E3 & & & & \\
\hline & Aggregation & & & & \\
\hline
\end{tabular}

The result can be compared with aggregate fuzzy numbers according to Eq. (2) and can be calculated by aggregating sub-criteria:

$\tilde{a}_{12}=(0,0,0.4) \otimes(0.33) \oplus(0.1,0.5,0.9) \otimes(0.33) \oplus(0.1,0.5,0.9) \otimes(0.33)=(0.05,0.33,0.733)$

With regard to the integration of the following comparison criteria, fuzzy numbers are to this point in the relationship non fuzzy numbers are converted using Eq. 3. For example, we have the following:

$$
a_{12}=\frac{0.05+0.33+0.733}{3}=1.122
$$


2816

After removal of the non-fuzzy fuzzy numbers, the following criteria must be paired comparison matrix defuzzy the Eq. 4.

$A_{\text {quality }}=\left[\begin{array}{cc}1 & 2.27 \\ 0.812 & 1\end{array}\right]$

Normalizing $A_{\text {quality }}$ yields,

$A_{\text {quality-normal }}=\left[\begin{array}{cc}0.5518 & 0.528 \\ 0.4481 & 0.4712\end{array}\right]$

At this point, using Eq. 5 and Eq. 6, we can determine the weight of each criteria shown in Table 5.

$W_{11}=\frac{1}{2} \sum_{j=1}^{n} \frac{a_{1 j}}{a_{1 j}+a_{2 j}}=\frac{1}{2}\left(\frac{0.5518}{0.5518+0.4481}+\frac{0.528}{0.528+0.4712}\right)=0.5399$

$\widetilde{F S}_{\text {Quality }}=(0.033,0.156,0.561) \otimes(0.5518) \oplus(0.033,0.156,0.561) \otimes(0.4598)=(0.33,0.15,0.5670)$

$F S_{\text {Quality }}=0.35$

Table 5

Score of criteria as input to the proposed model

\begin{tabular}{|c|c|c|c|c|c|}
\hline Criteria & Sub-criteria & $S_{i j}$ & $W_{i j}$ & $F S_{i}$ & Input \\
\hline \multirow{2}{*}{$U_{1}$} & $\mathrm{U}_{11}$ & $(0.033,0.156,0.561)$ & 0.5518 & \multirow{2}{*}{$(0.33,0.15,0.56)$} & \multirow{2}{*}{0.35} \\
\hline & $\mathrm{U}_{12}$ & $(0.033,0.156,0.561)$ & 0.4598 & & \\
\hline \multirow{5}{*}{$U_{2}$} & $\mathrm{U}_{21}$ & $(0.429,0.693,0.957)$ & 0.3402 & \multirow{5}{*}{$(0.3,0.49,0.82)$} & \multirow{5}{*}{0.54} \\
\hline & $\mathrm{U}_{22}$ & $(0.231,0.429,0.759)$ & 0.222 & & \\
\hline & $\mathrm{U}_{23}$ & $(0.198,0.264,0.594)$ & 0.1786 & & \\
\hline & $\mathrm{U}_{24}$ & $(0.198,0.264,0.594)$ & 0.1638 & & \\
\hline & $\mathrm{U}_{25}$ & $(0.231,0.429,0.759)$ & 0.1632 & & \\
\hline \multirow{3}{*}{$U_{3}$} & $\mathrm{U}_{31}$ & $(0.264,0.264,0.924)$ & 0.4647 & \multirow{3}{*}{$(0.29,0.38,0.48)$} & \multirow{3}{*}{0.51} \\
\hline & $\mathrm{U}_{32}$ & $(0.396,0.528,0.792)$ & 0.3 & & \\
\hline & $\mathrm{U}_{33}$ & $(0.231,0.429,0.759)$ & 0.2369 & & \\
\hline \multirow{2}{*}{$U_{4}$} & $\mathrm{U}_{41}$ & $(0.033,0.165,0.561)$ & 0.6752 & \multirow{2}{*}{$(0.10,0.19,0.67)$} & \multirow{2}{*}{0.33} \\
\hline & $\mathrm{U}_{42}$ & $(0.264,0.264,0.924)$ & 0.3247 & & \\
\hline \multirow{3}{*}{$U_{5}$} & $\mathrm{U}_{51}$ & $(0.231,0.429,0.759)$ & 0.4639 & \multirow{3}{*}{$(0.22,0.34,0.74)$} & \multirow{3}{*}{0.44} \\
\hline & $\mathrm{U}_{52}$ & $(0.198,0.264,0.594)$ & 0.3014 & & \\
\hline & $\mathrm{U}_{53}$ & $(0.264,0.264,0.924)$ & 0.2365 & & \\
\hline
\end{tabular}

Now, the phase model is available to be used. Fig. 4 shows a phase model in the condition that it has accepted the input vector of 5 criteria related to the input which is a number between zero and one and when this program is executed, the confidence of the outsourcing is calculated.

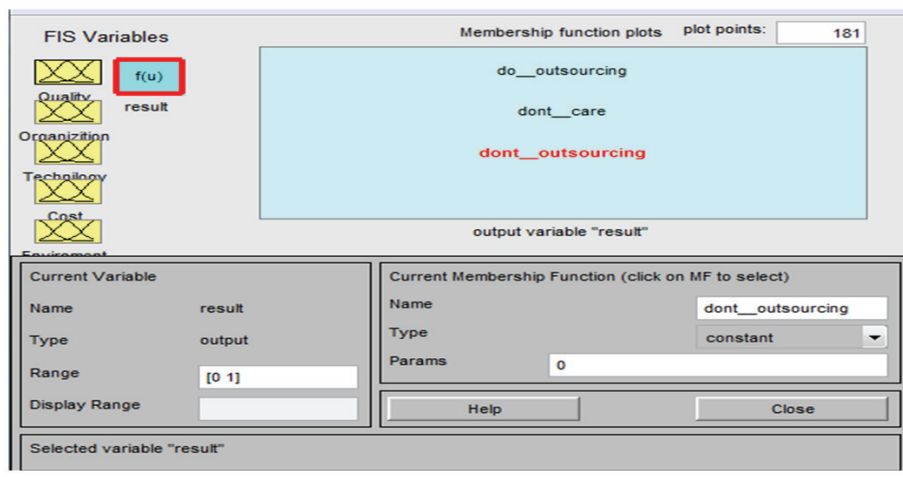

Fig. 4. Output membership

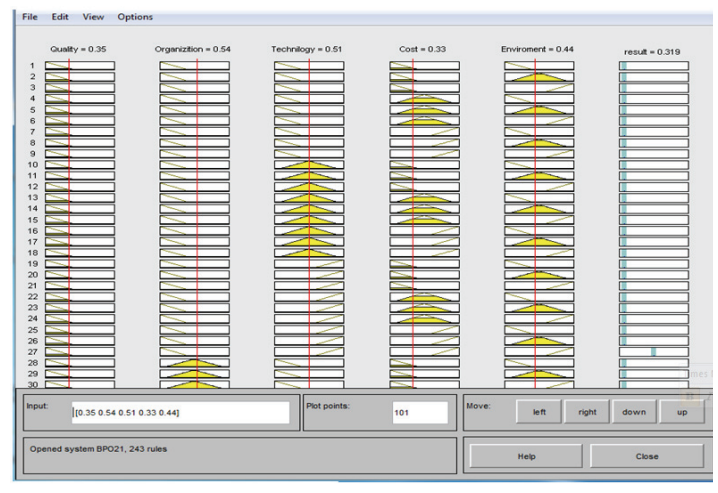

Fig. 5. The results of the proposed model 
The output will be between 0 and +1 in which zero shows the weakest tendency to outsourcing,+1 shows the strongest and 0.5 demonstrates the neutral case show in Fig 5. According to the model number 0.319 shown in Fig. 5, we can conclude that outsourcing is not working on behalf of an organization.

\section{Conclusion}

In a competitive environment, organization's success depends heavily on fast and impromptu decisions made by managers. However, mangers are not confidant in their decision-making and they look for an easy and effective method to make the correct and the best timely decision in the world with uncertain events. In a decision making process, using linguistic variables (fuzzy environment) eases the judgment for decision makers. The main purpose of this paper was to introduce a comprehensive decision making method for outsourcing. In the interim, the presented model sounds easier and more effective for managers because it has attempted to consider all effective decision making factors. AHP has been exercised in this model to solve evaluation problems of subjunctive elements and main elements identification and triangular fuzzy numbers have been used to determine the relative importance of different criteria. Decision makers can use MATLAB software outcome to make their decisions. The regulations in this software indicate what order organizations need to follow for the purpose of identifying effective factors for in-sourcing and outsourcing. The feature presented in this paper was that this model could determine the tendency or non-tendency degree of outsourcing considering the probability in fuzzy type.

\section{Reference}

Barthélemy, J. (2011). The Disney-Pixar relationship dynamics: Lessons for outsourcing vs. vertical integration. Organizational Dynamics, 40, 43-48

Bunyaratavej, K., Hahn, E., \& Doh, J. (2008). Multinational investment and host country development: Location efficiencies for services offshoring. Journal of World Business, 43(2), $227-242$.

Bunyaratavej, K., Hahn, E., \& Doh, J. (2007). International offshoring of services: A parity study. Journal of International Management, 13(1), 7-21.

Chen, K. S., \& Chen, K. L. (2006). Supplier selection by testing the process incapability index. International Journal of Production Research , 44(3), 589-600.

Di Gregorio, D., Musteen, M., \& Thomas, D. (2009). Offshore outsourcing as a source of international competitiveness for SMEs. Journal of International Business Studies, 40(6), 969988.

Doig, S.J., Ritter, R.C., Speckhals, K., \& Woolson, (2001). Has outsourcing gone too far? (Cover story). McKinsey Quarterly, 4, 24-37.

Franceschini, F., Galetto, M., Pignatelli, A., \& Varetto, M. (2003). Outsourcing: Guidelines for a structured approach. Benchmarking an International Journal, 10(3), 246-260.

GJ, U. (1996). Management of information technology using analytic hierarchy process.. Managing Virtual Enterprises , 690-697.

Graf, M., \& Mudambi, S. (2005). The outsourcing of IT-enabled business processes: A conceptual model of the location decision. Journal of International Management, 11(2), 253-268.

Hafeez, K., Malak, N., \& Zhang, Y. (2007). Outsourcing non-core assets and competences of a firm using analytic hierarchy process. Computers and Operations Research, 34(12), 3592-3608.

Handley, S., \& Benton, W. C., Jr (2009). Unlocking the business outsourcing process model. Journal of Operations Management, 27(5), 344-361.

Harland, C., Knight, L., Lamming, R., \& Walker, H. (2005). Outsourcing: assessing the risks and benefits for organisations, sectors and nations. International Journal of Operations \& Production Management, 25(9), 831-850. 
Harland, C., Knight, L., Lamming, R., \& Walker, H. (2005). Outsourcing: assessing the risks and benefits for organisations, sectors and nations. International Journal of Operations \& Production Management, 25(9), 831-850.

Hätönen, J., \& Eriksson, T. (2009). 30+ years of research and practice of outsourcing Exploring the past and anticipating the future. Journal of International Management, 15(2), 142-155.

Hätönen, J. (2009). Making the locational choice: A case approach to the development of a theory of offshore outsourcing and internationalization. Journal of International, 15(1), 61-76.

Helper, S., \& Sako, M. (1995). Supplier relations in Japan and the United States: Are they converging?. Sloan Management Review, 36(3), 77-84.

Hoecht, A. \&. T. P. (2006). Innovation risks of strategic outsourcing. Technovation, 26(5-6), 672681.

Jennings, D. (2002). Strategic sourcing: benefits, problems and a contextual model. Management Decision, , 40(1), 26-34.

Ketler K, W. J. (1993). The outsourcing decision. International Journal of Information Management, 13, 449-459.

Kremic, T., Tukel, O., \& Rom, W. (2006). Outsourcing decision support: A survey of benefits, risks, and decision factors. Supply Chain Management: An International journal, 11(6), 467-482.

Lacity, M.C., Willcocks, L.P., \& Feeny, D.F. (1996). The value of selective IT sourcing. Sloan Management Review, 37(3), 13-25.

Landis, K.M., Mishra, S., \& Porrello, K. (2005). Calling a change in the outsourcing, s.1.: Deloitte Consulting Report.

Larsen, M. P. T. \&. S. D., (2010). Lego group. Volume 9B10M094 (pp. 1-16).

Lasch, R., \& Janker, C. (2005). Supplier selection and controlling using multivariate analysis. International Journal of Physical Distribution and Logistics Management, 35(6), 409-425.

Lee, J.N., \& Kim, Y.G. (1999). Effect of partnership quality on IS outsourcing success:Conceptual framework and empirical validation. Journal of Management Information Systems, 15(4), 29-61.

McCarthy I, A. A. (2004). The impact of outsourcing on the transaction costs and boundaries of manufacturing. International Journal of Production Economics , 88, 61-71.

McHugh, M., Humphreys, P., \& McIvor, R. (2003). Buyer-supplier relationships and organizational health. Journal of Supply Chain Management, 39(2), 15-25.

Nistorescu, T., \& Barbu, C, (2009). Outsourcing: long-term competitive strategy. Metalurgia International, 14(6), 22-26.

Power, M. B. C. \&. D. K. (2004). The ten outsourcing traps to avoid. Journal of Business Strategy, 25(2), 37-42.

Rese, M. (2006). Successful and sustainable business partnerships: How to select the right partners?. Industrial Marketing Management, 35(1), 72-82.

Robinson, P., Lowes, P., Loughran, C., Moller, P., Shields, G., Klein, E. (2008). Why Settle for Less, s.l.: Outsourcing Report.

Spekman, R., \& Caraway, R. (2006). Making the transition to collaborative buyer-supplier relationships:An emerging framework. Industrial Marketing Management, 35(1), 10-19.

Tseng, Y. J., \& Lin, Y. H. (2005). A model for supplier selection and tasks assignment. Journal of American Academy of Business, 6(2), 197-207.

U., A. (2000). New dimensions of outsourcing: a combination of transaction cost economics and the core competencies concept. European Journal of Purchasing and Supply Management, 23-9.

U, K. (1996). Grundsatzliche Uberlegungen zum Outsourcing. In: s.l.:s.n., 1-9.

Wu, L., \& Park, D. (2009). Dynamic outsourcing through process modularization. Business Process Management, 15(2), 225-244.

Zadeh, (1965). Fuzzy sets. Information and Control, 8, 338-353.

Zaheer, S., Lamin, A., \& Subramani, M. (2009). Cluster capabilities or ethnic ties?Location choice by foreign and domestic entrants in the services offshoring industry in India. Journal of International Business Studies, 40(6), 944-968. 